\title{
Comparative study of Watson's and Cairns's trabeculectomies in a Black population with open angle glaucoma
}

\author{
ROBERT DAVID, JEFFREY FREEDMAN, AND MAURICE H. LUNTZ \\ From the Glaucoma Clinic, St. John Eye Hospital, Baragwanath Hospital and University of the \\ Witwatersrand, Johannesburg, South Africa
}

SUMMARY A comparative study of the effectiveness of Watson's and Cairns's trabeculectomy in a Black South African population with open-angle glaucoma is presented. The eventual success rate of $91.6 \%$ is comparable with that found in Whites, and the results were similar with both methods.

Conflicting results have been obtained by different authors with filtering operations in Black populations (Iliff, 1944; Berson et al., 1966; Welsh, 1969; and Luntz, 1965). Similarly when reviewing trabeculectomies in Negro eyes the results have been conflicting. Chatterjee and Ansari (1972) had good results on their patients in Ghana using Cairns's trabeculectomy, while Welsh (1972) employing the same technique in South Africa reported only $19 \%$ success rate. Freedman (1976) in his series of Watson's trabeculectomy on American Negroes reported an $80 \%$ success rate.

We report on the results of a retrospective study comparing the efficacy of the Cairns and Watson types of trabeculectomy, performed on a Black South African population suffering from open angle glaucoma. Although results in this population with the classical filtration operations are good (Luntz, 1965), trabeculectomy has the advantage of fewer postoperative complications.

\section{Materials and methods}

A total of 34 patients- 22 males and 12 femalestheir ages ranging from 35 to 75 , had surgical treatment. There were 49 eyes on which 61 trabeculectomies were performed. All the patients were seen at the Glaucoma Clinic, St. John Eye Hospital, Baragwanath, and underwent trabeculectomy between 1 January 1974 and 31 December 1975.

In all these patients medical treatment failed to control their glaucoma. Failure was judged by con-

Address for reprints: Dr R. David, Department of Ophthalmology, University of the Witwatersrand Medical School, Hospital Street, Johannesburg 2001, South Africa. tinuing field loss and constantly elevated pressures despite maximal medical therapy. Prior to surgery, all patients were admitted to hospital and diurnal curve studies on full medication for 4 to 10 days were done.

The surgical techniques used were those described by Cairns (1970) and modified by Watson (1972).

The procedure followed was: a conjunctival flap was raised in the upper nasal or upper temporal quadrant and $3 \times 3 \mathrm{~mm}$ superficial scleral flap of $\frac{1}{2}$ thickness dissected and hinged on the cornea. A flap $2 \times 2 \mathrm{~mm}$ in size was dissected in the underlying sclera from clear cornea to scleral spur. This deep corneo-scleral flap was excised and a peripheral iridectomy performed. The superficial flap was closed with 4 to $610 / 0$ nylon sutures and the conjunctival flap sutured with 10/0 nylon.

When using the Watson procedure (Watson, 1972) dissection of the deep scleral flap $(2 \times 3 \mathrm{~mm})$ was commenced $1 \mathrm{~mm}$ behind the scleral spur dissecting towards the cornea. At the scleral spur the ciliary body was dissected off by blunt dissection producing a cyclodialysis. The flap was dissected forward to clear cornea and then excised.

Both procedures were done using the operating microscope, with zoom-lens facilities. Anaesthesia was either local or general and identical postoperative treatment was given to all patients: cycloplegic and steroid drops 3 to 4 times a day for 10 days.

\section{Results}

The follow-up period ranged from a minimum of 6 months to a maximum of 30 months, 24 patients $(70 \cdot 5 \%)$ being followed up for more than a year. 
The operation was considered to be successful if intraocular pressure was $20 \mathrm{~mm} \mathrm{Hg}$ or less, with or without additional medication for the total follow-up period.

Table 1 summarises the results of the two procedures done as the first operation. Both techniques were equally successful in controlling intraocular pressure (Watson's $73.3 \%$ and Cairns's $73.6 \%$ ).

Thirteen of the initial trabeculectomy procedures were failures (Table 1). Of these 12 had a second trabeculectomy, by either the Cairns or Watson method. One patient refused further surgery. The results of these repeated trabeculectomies can be seen in Table 2. Three out of the five reoperations by the Watson technique and five out of the seven by the Cairns method were successful. Therefore of 48 eyes with open angle glaucoma which had one or more operations 44 were eventually controlled by surgery, a success rate of $91.6 \%$.

The average preoperative intraocular pressure was $28.9 \mathrm{mmHg}$ in those patients who had successful Watson type trabeculectomy as compared with $30.9 \mathrm{mmHg}$ in patients who had a successful Cairns procedure. The average preoperative pressure in the failures was $27 \cdot 8$ and $29 \cdot 3 \mathrm{mmHg}$ respectively.

Thirteen patients (15 eyes) required additional medication to control intraocular pressure after a Watson trabeculectomy and 12 patients (16 eyes) after the Cairns method.

\section{COMPLICATIONS}

Complications were minimal in those eyes operated on by the Cairns technique. Only two showed shallow anterior chamber postoperatively, one with a choroidal detachment. These resolved spontaneously within a few days. Those operated on by the Watson method developed more postoperative complications. The commonest was hyphaema. Other complications included shallow anterior chamber (3), all of which resolved spontaneously, severe

Table 1 Results of first operations

\begin{tabular}{|c|c|c|c|}
\hline & Watson & Cairns & Total \\
\hline $\begin{array}{l}\text { Number of Operations } \\
\text { Success } \\
\text { Failure } \\
\% \text { Success rate }\end{array}$ & $\begin{array}{c}30 \\
22 \\
8 \\
73 \cdot 3\end{array}$ & $\begin{array}{c}19 \\
14 \\
5 \\
73 \cdot 6\end{array}$ & $\begin{array}{l}49 \\
36 \\
13 \\
73 \cdot 4\end{array}$ \\
\hline
\end{tabular}

Table 2 Results of 12 trabeculectomy reoperations

\begin{tabular}{|c|c|c|c|c|}
\hline \multicolumn{2}{|l|}{ Watson } & \multicolumn{2}{|l|}{ Cairns } & \multirow[t]{2}{*}{ Total } \\
\hline Success & Failure & Success & Failure & \\
\hline 3 & 2 & 5 & 2 & 12 \\
\hline
\end{tabular}

uveitis, in one eye, and cataract one month after surgery in one eye.

\section{Discussion}

The Watson and Cairns methods of trabeculectomy were compared in 49 eyes of Black South African patients with open angle glaucoma. The degree of success after the first operation was similar in both, Watson's method $73.3 \%$ and Cairns's method $73.6 \%$.

Trabeculectomy eventually controlled the disease in $91.6 \%$ of the eyes subjected to surgery. This result in South African Blacks is far more optimistic than those reported by Welsh (1972) in a similar population and compares favourably with the results of classical filtration operations in the same population (Luntz, 1965), and the more recent report in an American Black glaucoma population by Freedman et al. (1976).

These results are similar to the findings of other investigators reporting on White glaucoma populations (D'Ermo and Bonomi, 1973; Thyer and Wilson, 1972; Jerndal and Kriisa, 1974; Ridgway, 1974; and Watson and Barnett, 1975).

Twelve eyes in our series were operated on more than once and of these operations eight were successful. Although these figures are too small to draw meaningful conclusions it seems that repeat trabeculectomies in Black people are more successful than repeat operations in other types of filtration surgery (Luntz, 1970).

The preoperative intraocular pressure does not seem to influence the final outcome, and the drop in pressure after successful surgery was similar with both techniques.

Our analysis has shown that the final postoperative result is similar whether the Cairns or Watson technique is used. The operation of trabeculectomy works well in Black patients with open angle glaucoma. Immediate postoperative complications are fewer with the Cairns technique than with the Watson method. These complications were similar to those described by Ridgway et al. (1972) and Watson and Barnett (1975).

\section{Conclusions}

From the above study it seems that trabeculectomy is a good procedure in open angle glaucoma in Black South Africans. Irrespective of the type of surgery the final results were the same. There were fewer complications with the Cairns procedure.

We wish to thank the Medical Superintendent of the Baragwanath Hospital for permission to publish. 
Thanks are also due to the registrars working in the Glaucoma Clinic for their assistance.

\section{References}

Berson, D., Zaubermann, H., Landau, L., and Blumenthal, M. (1966). American Journal of Ophthalmology, 62, 509.

Cairns, J. E. (1970). Advances in Ophthalmology, 22, 143.

Chatterjee, S., and Ansari, M. W. (1972). British Journal of Ophthalmology, 56, 783.

D’Ermo, F., and Bonomi, L. (1973). Ophthalmologica (Basel), 166, 311.

Freedman, J., Shen, E., and Ahrens, M. (1976). British Journal of Ophthalmology, 60, 573.
Iliff, C. E. (1944). American Journal of Ophthalmology, 33, 1253.

Jerndal, T., and Kriisa, V. (1974). British Journal of Ophthalmology, 58, 927.

Luntz, M. H. (1965). South African Medical Journal, 39, 955.

Luntz, M. H. (1970). South African Medical Journal, 44, 6.

Ridgway, A. E., Rubinstein, K., and Smith, V. H. (1972). British Journal of Ophthalmology, 56, 511.

Ridgway, A. E. (1974). British Journal of Ophthalmology, 58, 680 .

Watson, P. G. (1972). British Journal of Ophthalmology, 56, 299.

Watson, P. G., and Barnett, F. (1975). American Journal of Ophthalmology, 79, 831.

Welsh, N. H. (1972). British Journal of Ophthalmology, 56, 37. 